\title{
Impact of rabies vaccination history on attainment of an adequate antibody titre among dogs tested for International Travel Certification, Israel - 2010-2014
}

Article

Accepted Version

Yakobson, B., Taylor, N., Dveres, N., Rotblat, S., Spero, Ż., Lankau, E. W. and Maki, J. (2017) Impact of rabies vaccination history on attainment of an adequate antibody titre among dogs tested for International Travel Certification, Israel - 20102014. Zoonoses and public health, 64 (4). pp. 281-289. ISSN 1863-2378 doi: https://doi.org/10.1111/zph.12309 Available at https://centaur.reading.ac.uk/68401/

It is advisable to refer to the publisher's version if you intend to cite from the work. See Guidance on citing.

To link to this article DOI: http://dx.doi.org/10.1111/zph.12309

Publisher: Wiley

All outputs in CentAUR are protected by Intellectual Property Rights law, including copyright law. Copyright and IPR is retained by the creators or other copyright holders. Terms and conditions for use of this material are defined in the End User Agreement. 


\section{www.reading.ac.uk/centaur}

\section{CentAUR}

Central Archive at the University of Reading

Reading's research outputs online 
1 Impact of rabies vaccination history on attainment of an adequate antibody titre among

2 dogs tested for international travel certification, Israel - 2010-2014

3 Boris Yakobson ${ }^{1, *}$, Nick Taylor ${ }^{2}$, Nelli Dveres ${ }^{1}$, Shira Rotblut ${ }^{1}$, Sinaida Spero ${ }^{3}$, Emily W.

$4 \quad$ Lankau $^{4}$, Joanne Maki ${ }^{5}$

5 1. Rabies Department, Kimron Veterinary Institute, 20250, Bet Dagan, Israel; 2. Veterinary

6 Epidemiology and Economics Research Unit (VEERU) \& PAN Livestock Services Ltd.,

7 University of Reading, School of Agriculture, Policy and Development, Reading, RG6 6AR,

8 UK; 3. Koret School of Veterinary Medicine, The Hebrew University of Jerusalem, P.O. Box

9 12, Rehovot, 76100 Israel; 4. LandCow Consulting, P. O. Box 5651, Madison, WI, 53705,

10 USA; Ronin Institute, Montclair, NJ, USA; 5. Merial Ltd., 115 Transtech Drive,Athens, GA

11 30601, USA; *Correspondence: Boris Yakobson, Rabies Department, Kimron Veterinary

12 Institute, 20250 Bet Dagan, Israel; Tel.: +972 506241352;E-mail address:

13 borisy@moag.gov.il

14 Impacts

15 - Many countries require demonstration of an adequate level of anti-rabies antibodies in the

16 blood (i.e., rabies titre of $0.5 \mathrm{IU} / \mathrm{ml}$ ) to permit entry of dogs traveling internationally.

17 - We analysed rabies titres of dogs seeking travel certification in Israel to assess

18 demographic and vaccine history factors associated with not having an adequate rabies

19 virus neutralizing antibody (RVNA) titre for travel certification.

20 - Only having received one previous rabies vaccination and a longer time since the last

21 vaccination was received were associated with not achieving an adequate RVNA titre for

22 travel certification.

23 - These findings reiterate the importance of the first booster vaccination for ensuring dog

24 populations are protected against rabies. 
27 Rabies is endemic in wildlife or domestic carnivore populations globally. Infection of domestic dogs is of particular concern in many areas. In regions where domestic animals are at risk of exposure to rabies virus, dogs should be routinely vaccinated against rabies to protect both pet and human populations. Many countries require demonstration of an adequate level of serum rabies neutralizing antibodies to permit entry of dogs during international travel. We analysed rabies titres of dogs seeking travel certification in Israel to assess demographic and vaccine history factors associated with antibody titres below the acceptable threshold for travel certification. Having received only one previous rabies vaccination and a longer duration since the most recent vaccination was received were primary risk factors for not achieving an adequate RVNA titre for travel certification. These risk factors had stronger effects in younger animals, but were consistent for dogs of all ages. In particular, these findings reiterate the importance of administering at least two rabies vaccinations (the primo vaccination and subsequent booster) to ensure population-level protection against rabies in dogs globally.

Key words: dogs, global travel, immunity, Israel, prevention, rabies, serology, vaccination Introduction

Rabies is endemic in wildlife and domestic carnivore populations globally. In regions where domestic animals are at risk of rabies virus exposure, dogs should be routinely vaccinated against rabies to protect both pet and human populations from this nearly invariably fatal infection (WHO, 2015). In many countries rabies vaccination protocols are legally prescribed. Proof of rabies vaccination is typically required as a condition for international pet travel, both due to the risk of rabies virus exposure in endemic destinations and the risk of rabies virus introduction to rabies-free areas by unimmunized animals during travel 
include a combination of age and identification method (e.g., microchipping) requirements, documentation of having received rabies vaccine a sufficient duration prior to travel to mount an immune response (i.e., proof of vaccination), serologic demonstration of immunity prior to travel, or a quarantine period before or after arrival (examples of different country requirements may be located at USDA, 2015).

During the early 1990s, many countries converted from a strict quarantine requirement for domestic dog entry to requiring serological evidence of immunity (Cliquet et $a l ., 2003)$. These changes were driven by both increasing interest in free-circulation of people and animals among countries and improved scientific understanding of the relationship between rabies antibody titre levels in dogs and cats and resistance to infection upon exposure (Aubert 1992, WHO 1992, Cliquet et al., 2003). In challenge experiments, a rabies virus neutralizing antibody (RVNA) titre of $\geq 0.5$ international units (IU) $/ \mathrm{ml}$ correlated best with protection from rabies virus infection on exposure (Aubert, 1992). The World Health Organization (WHO) designated RVNA titres of $\geq 0.5 \mathrm{IU} / \mathrm{ml}$ in an actively immunized dog $>16$ weeks of age as the standard for certifying protection against rabies infection (WHO, 1992). Since 1993, the World Organization for Animal Health (OIE) has recommended requiring serologic evidence of immunity by quantification of RVNA whenever dogs or cats are imported from countries with endemic rabies virus circulation to areas that are considered rabies free (OIE, 1996). Many countries require demonstration of an adequate RVNA titre $(\geq 0.5 \mathrm{IU} / \mathrm{ml}$ ) for international movement of pets (in the European Union for example: EU, 2003). Dogs with lower titres or even without detectable antibodies have survived virulent rabies challenge (Sikes et al., 1971; Brown et al., 1973; Barth and Jaeger, 1977; Ganiere et al., 1989; Aubert, 1992).

In Israel, rabies is a notifiable disease according to the Animal Disease Ordinance (New Version) of 1985 and the Rabies Ordinance of 1934 (FAO, 2001; Israel Ministry of 
Agriculture and Rural Development, 1934). Since 1956, domestic dogs in Israel must be vaccinated against rabies by law, first at three months old and then annually (Israel Ministry of Agriculture and Rural Development, 2015). Legally mandated vaccination of dogs substantially shifted the dominant rabies reservoir. While dogs were the most commonly affected through the mid-1950s (Nobel \& Neumann, 1962; Yakobson et al., 2004), red foxes (Vulpes vulpes) and to a lesser extent golden jackals (Canis aureus) became the primary rabies reservoirs after 1956. During the mid-1970s, sylvatic fox rabies virus variant surpassed the canine variant (Yakobson et al., 1998). Since 1998 wildlife rabies has been controlled through the use of oral rabies vaccines (Yakobson et al., 2006). However, despite mandatory dog vaccination, canine rabies has re-emerged in northern Israel, resulting in rabies cases in unvaccinated dogs and other species (David et al., 2009; David, Bellaiche, and Yakobson, 2010; David and Yakobson, 2011).

Given continued rabies virus transmission in Israel, dogs must be tested to ensure adequate RNVA titres ( $\geq 0.5 \mathrm{IU} / \mathrm{ml}$ ) for travel certification. This study used data obtained from routine pre-travel testing of dogs to explore factors associated with failure to achieve adequate RNVA titres for travel in vaccinated dogs. We consider how these findings may inform broader discussions about vaccination strategies for domestic pets.

\section{Materials and methods}

\section{Data source}

Dogs travelling to certain countries outside of Israel are required to have an RVNA titre $\geq 0.5$ IU/ml (hereafter referred to as an adequate RVNA titre for travel). The National Rabies Laboratory at the Kimron Veterinary Institute, part of the Israeli Veterinary Services and Animal Health (IVSAH), has performed travel certification serology (hereafter referred to as a pre-travel titre) since 2004. The laboratory is accredited by the National Laboratory Accreditation Authority and annually meets the requirements of inter-laboratory testing 
organized by the EU-designated Institute AFSSA-Nancy (France). Serum RVNA were measured using the rapid fluorescent focus inhibition test (RFFIT; Smith et al., 1973, modified by Zalan et al., 1979).

Dog licensure is mandatory in Israel and requires identification by microchip, registration in a central database and having recorded vaccination against rabies during the last year. Annual re-vaccination is required to maintain validity. The IVSAH is responsible for management of the national computerized dog registration database, which includes each animal's age, sex and vaccination history.

\section{Study design}

110 Data were extracted from the IVSAH national dog registration database held by including a study population of dogs presented for travel certification RVNA titres from 3rd January 2010 to 19th May 2014. The following variables were extracted from the national registry for each dog as explanatory variables (i.e., putative risk factors): sex; age at most recent rabies vaccination prior to blood draw for the pre-travel titre (in months; hereafter "age at most recent vaccination"); number of rabies vaccinations prior to blood draw for the pre-travel titre

116 (hereafter "number of previous vaccinations"), and time between the most recent rabies vaccination and blood draw for a pre-travel titre (in days; hereafter "gap between vaccination and titre"). These records were linked to the date and outcome of the pre-travel titre reported by the Kimron Veterinary Institute by microchip identification number. Microchip numbers were subsequently removed to protect owner privacy.

We then performed a retrospective case-control analysis, where cases were defined as dogs presented for testing that did not achieve an adequate RVNA titre for travel, and controls were those presented for testing that $\mathbf{d i d}$ achieve an adequate RVNA titre for travel.

124 Controls were randomly selected stratified by year with a 1:1 case-to-control ratio using the 
random number function in Microsoft Excel (v. 2010, Microsoft Corporation, Washington,

126 USA).

\section{Data analysis}

128 Associations among putative risk factors and between these factors and titre status (case or

129 control) were assessed using a Spearman's rho rank correlation for associations between two

130 continuous variables, a t-test between continuous and binary variables, or the $X^{2}$ or Fisher's exact test between two binary variables. Strength of associations was expressed as an odds ratio (OR) with 95\% confidence interval (CI; Taylor series, Dean, Sullivan and Soe, 2015). An odds ratio that is significantly greater than one indicates that the risk factor is associated with increased likelihood of failing to achieve an adequate RVNA titre for travel. Where significant associations between risk factors were detected, stratified analyses were performed to consider the effects of confounding on univariate results. factors were transformed into binary categories for some analyses. Categories were defined by visual examination of each variable's distribution for natural breaks or based on pertinent

140 biological information (e.g., 15 months is the age at which dogs would typically receive a second rabies vaccination). Continuous variables converted to binary categories were age at most recent vaccination ( $\leq 15$ month old or $>15$ months old), number of previous vaccinations (only one vaccination or $>1$ vaccination received), and the gap between vaccination and titre

$144 \quad(\leq 60$ days or $>60$ days).

Multivariate logistic regression modelling was then performed to provide adjusted

146 ORs for each risk factor. Logistic regression with forwards and backwards stepwise model

147 selection was performed, with the criteria for entry and exit of parameters being a significant

148 change in the model deviance as judged by a p-value of $\leq 0.1$. 
First, a "base" model was constructed for model selection using all putative risk factors (sex, age at most recent vaccination, number of previous vaccinations, and the gap between vaccination and titre). Different variables were offered as starting variables in repeated runs to assure that the final model was not dependent on the order of factor entry and exit. This base model had no restrictions on variable entry or exit from the model. We then constructed additional multivariable logistic regression models to consider potential confounding between age at most recent vaccination and other putative risk factors before arriving at a final model. Due to concern that effects of age at most recent vaccination could be confounded by associations with other variables, a second model was constructed in which the age at most recent vaccination variable was forced to remain in all models through the model selection process ("age forced" model). Next, two age-stratified models were constructed by model selection, one using only the data for young animals ( $\leq 15$ months at most recent vaccination; "young" model) and one using only the data for adult animals (>15 months at most recent vaccination; "adult" model). Then, a final model was built guided by the findings of these exploratory models and including biologically relevant interaction terms. associations among multiple factors and failure to achieve an adequate RVNA titre for travel that were then used to estimate the odds of failing to achieve an adequate RVNA titre for travel (i.e., scenario risk assessments), given specific combinations of factors (scenarios) for variables included in the model (e.g., for a young dog, having had only one vaccination within 60 days of the test). Odds was converted to probability (risk) of failing to achieve an adequate RVNA titre for travel using the equation: probability = odds/(1+odds). population, a sample was extracted from Israel's national dog registration database to serve as a snapshot of the overall registered dog population's vaccination history. Demographic and 
vaccine history of the registered dog population during August 2013 was qualitatively compared to the population of dogs presented for travel certification during 2013.

All statistical tests and regression modelling were carried out using the statistical package Statistix version 10 (C 1985-2013 Analytical Software, Tallahassee, FL, USA).

\section{Results}

\section{Sample description}

From 3rd January 2010 to 19th May 2014, 4,949 dogs presented for travel certification, evenly distributed across years (range of 1,000-1,200 dog/year). Of these, 395 (8.0\%) did not have an adequate RVNA titre for travel but many of these did have detectable RVNA below $0.5 \mathrm{IU} / \mathrm{ml}$ (for these, median titre=0.18 IU, range=0.02-0.48 IU). Forty nine of these 395 cases were excluded due to incomplete records for one or more necessary variables. Therefore 346 cases and 346 controls (692 dogs total) were selected for analysis.

\section{Univariate and stratified analysis}

Approximately half of both cases (49\%) and controls (47\%) were male (Table 1a). A significantly larger portion of cases received only one vaccination prior to presentation for pre-travel titre ( $85 \%$ versus $35.3 \%$ of controls), had received the most recent vaccination at $\geq$ 15 months old (62.4\% versus $27.5 \%$ of controls), and had a gap of $>60$ days between vaccination and titre $(80.3 \%$ versus $60.1 \%$ of controls; Table $1 \mathrm{a})$.

Mean gap between vaccination and titre did not differ significantly between cases (173 days) and controls (160 days; T-test: $\mathrm{p}$-value $=0.3896)$. However, despite similar means, the distribution of gap between vaccination and titre was different between cases and controls (Figure 1). Specifically, $40 \%$ of test dates for the controls fell within 60 days of the most recent vaccination compared to only $20 \%$ for the cases $\left(X^{2}\right.$ test: $\mathrm{p}$-value $\left.<0.0001\right)$. Assessment of associations among these putative risk factors revealed a notable potential confound between the number of previous vaccinations and the age at most recent 
vaccination. Both variables differed significantly between cases and controls as both binary categories (Table 1a) and in the original continuous variable (Spearman rank coefficient $=0.6854, \mathrm{p}$-value $<0.0001 ;$ Table 2$).$ The mean age at most recent vaccination for dogs having received only one previous vaccination was 15.5 months, compared with 53.3 months for dogs that had received more than one previous vaccination (T-test: $p$-value $<0.0001$; Table 2).

Given this association between age at most recent vaccination and number of previous vaccinations, two stratified analyses were performed. When stratified by the number of previous vaccinations, age at most recent vaccination was not significantly associated with not having an adequate RVNA titre for travel (i.e., being a case; Table $2 b$ ), yet when stratified by age at most recent vaccination, the number of previous vaccinations was significantly associated with the case outcome and with a similar OR for both age groups

\section{1 (Table 2c).}

Significant associations were not noted among other putative risk factors; for this

213 reason, additional bivariate analyses were not performed.

\section{Logistic regression modelling}

215 The base logistic regression model retained two significant factors: having only one previous rabies vaccination and having a $>60$ day gap between vaccination and titre (Table 3 ). When age at most recent vaccination was forced to remain in the model (age forced), age was not

218 significant and the model was otherwise similar to the base model, indicating no significant 219 direct influence of age. In the stratified models for either young or adult dogs, the ORs for number of previous vaccinations and gap between vaccination and titre differed from that in the base model (although with wider 95\% CIs), suggesting that age may have some modifying effect on the influence on these factors (Table 3). Finally, when interaction terms

223 (age at most recent vaccination $\mathrm{x}$ number of previous vaccinations, age at most recent 
vaccination $\mathrm{x}$ gap between vaccination and titre, and number of previous vaccinations $\mathrm{x}$ gap between vaccination and titre) were included in the final model selection, the interaction

226 between age at vaccination and gap between vaccination and titre was significant and both variables were retained in the final model (Table 4).

\section{Scenario risk estimation}

The highest estimated risk of failure to achieve an adequate RVNA titre for travel was for dogs tested $>60$ days after receiving their first vaccination $(81 \%$ for young dogs; $73 \%$ for adults; Figure 2). In contrast, estimate risk of failure to achieve an adequate RVNA titre for travel was lowest for dogs that had received one or more booster vaccination and were tested within 60 days of receiving the most recent vaccination ( $8 \%$ in young dogs; $13 \%$ is adults; Figure 2).

\section{Evaluation of study representativeness}

The snapshot of 367,388 registered dogs in the national dog registration database during August 2013 was compared to dogs in the study population during 2013. The registered dog population sex ratio (50\% male) was similar to that of travelling dogs $(48 \%)$. The proportion of young animals ( $\leq 15$ months) was less in the registered population (7\%) than for dogs presented for pre-travel testing (24\%). The difference in the proportion of dogs with only one vaccination was smaller: $29 \%$ of the registered dogs had only one rabies vaccination compared with $36 \%$ of the travelling dogs.

\section{Discussion}

Failure to achieve adequate RVNA titre for travel occurred in approximately $8 \%$ of the study population of dogs presenting for travel certification in Israel during January 2010-May 2014. However, many dogs failing to reach the threshold for travel certification $(0.5 \mathrm{IU} / \mathrm{ml}) \mathrm{did}$ have a detectable RVNA titre and may or may not have had sufficient protection against rabies virus if exposed. 

titre for travel (cases in this analysis) in primo vaccinates or dogs vaccinated $>60$ days prior to blood collection for titre. Effects of age (measured in this study as the age at most recent vaccination) were confounded by correlation of this variable with the number of previous vaccinations received. This association is not unexpected, as young animals will more typically have only received a single documented vaccination when dogs are receiving rabies vaccination on the recommended schedule. Stratified analysis suggested that the number of previous vaccinations was the driving variable in the observed relationship, with fewer dogs having received more than one vaccination in cases compared to controls in both the young $(\leq 15 \mathrm{mo})$ and older $(>15 \mathrm{mo})$ groups. In contrast, age group proportions did not differ between cases and controls when stratified by the number of previous vaccinations, a finding supported during exploratory multivariate analysis by the negligible impacts of forcing retention of the age at most recent vaccination variable during model selection.

The strongest explanatory variables in the final logistic model was the number of previous vaccinations, followed by the gap between vaccination and titre. In this model, age at most recent vaccination was not itself a significant effect but did significantly interact with the gap between vaccination and titre, with a higher odds of failure to achieve an adequate RVNA titre for travel in young animals with a >60 day gap. The estimated odds of failure to achieve an adequate RVNA titre for travel for dogs with only one previous rabies vaccination was approximately $3 \mathrm{x}$ higher than those with more than one previous vaccination if tested within 60 days and was $5 \mathrm{x}$ higher if tested after 60 days.

The sub-population of dogs presented for travel certification contained more young

271 dogs and more dogs with only one previous rabies vaccination compared to the registered dog 272 population in Israel. This suggests that the $8 \%$ of dogs that failed to achieve an adequate titre 273 for travel in the study population may be an overestimate for the general dog population in 
274 Israel. Of dogs in the study population that failed to achieve an adequate titre, $36 \%$ had

275

276

277

278

279

280

281

282

283

284

285

286

287

288

289

290

291

292

293

294

295

296

297

298

received only one vaccination when blood was drawn for pre-travel titre, whereas $29 \%$ of the general population had only one rabies vaccination.

These findings agree with previous work in assessing travel titre levels in dogs which generally find that age, time since vaccination, and in particular booster vaccination are critical factors for a reasonable assurance of protection against rabies during travel, as measured by adequacy of RVNA titre levels (Cliquet et al., 2003; Zanoni et al., 2010;

Berdtsson et al., 2011; Klevar et al., 2015). While dogs with titre values below the 0.5 IU threshold accepted for travel could be protected, assurance of protection is less certain below this accepted titre value (Aubert, 1992). The practical implication of these results is that dogs should not be considered to have strong assurance of being protected from rabies virus infection until they have received at least two vaccinations. While risk of failing to achieve an adequate titre for travel certification is highest in young dogs, who under current vaccination schedules in many countries will not receive a rabies booster vaccination until over one year of age, our study suggests that the risk for adult primo vaccinates is also elevated. Rescue animals in particular may be a particularly high-risk group for failure to achieve sufficient antibodies for assurance of protection due not only to being primo vaccinates but other health issues that my reduce vaccine efficacy in these populations (Klevar et al., 2015).

Dog rabies vaccination protocols are well established and largely agreed upon by public health advisory bodies and vaccine manufacturers (WHO, 1992; Brown et al., 2011; OIE, 2013). A single dose of rabies vaccine is generally sufficient to immunise, due to the potent glycoprotein $\mathrm{G}$ antigen included along with a powerful adjuvant (Petrovsky and Aguilar, 2004). Available canine rabies vaccines are licensed as providing either a one or three year duration of immunity (DOI) (Brown et al., 2011) and when required in regulations, the timing of subsequent doses is typically determined by this licensed DOI except for the 
timing of the first booster dose. To ensure adequate population-level protection, a second dose at up to a year after the first dose is strongly recommended to improve titres in individuals with insufficient primary antibody response (Brown et al., 2011). Low antibody production on initial vaccination is of particular concern in puppies due to potential interference from maternally derived antibodies.

In countries where dog vaccination is routine and obligatory, most puppies are born with protective levels of maternally derived antibodies that will gradually decline to a level that allows successful active immunization at between six and 12 weeks of age (Aghomo et al., 1990; Mitmoonpitak \& Tepsumethanon, 1998). In the period of waning of maternal antibodies prior to development of active immunity young animals may not be protected (Mitmoonpitak \& Tepsumethanon, 1998; Clark \& Wilson, 1996). Maternally-derived antibody levels and rate of decline vary such that some puppies may respond poorly to vaccination up to 12 weeks of age or older.

A common protocol for rabies vaccination specifies initial vaccination of puppies at eight to twelve weeks of age then a second vaccination one year later, followed by booster vaccinations at one or three year intervals, depending on the licensed DOI of the vaccine used and country regulations (Brown et al., 2011). In contrast, vaccination programs in canine rabies endemic areas assume that many puppies will not have maternal antibodies to interfere with primary vaccination. However, poor responders to primo vaccination will occur in all dog populations, resulting in a low but real risk for rabies in these animals if exposed to rabies virus.

The World Small Animal Veterinary Association recently recommended that a second dose of vaccine should be given two to four weeks after the first dose in high-risk regions, if permitted by law (Day et al., 2010). Similarly, the European Food Safety Authority has suggested that more proximate booster vaccination (within 4-6 weeks) would reduce risk of 
rabies translocation by insufficiently protected primo vaccinates even more effectively than

325

326

327

328

330

331

332

333

334

335

336 monitoring for a serologic threshold prior to travel (ESFA, 2006). However, compliance with a shortened booster schedule for rabies vaccination could be poor if recommendations are not aligned with other vaccination schedules. Further study would be beneficial to determine the ideal timing of the first booster vaccination to reduce the risk period during which titre levels may have fallen below the desired protection threshold in low-responders at primo vaccination. After receiving the first booster, providing additional booster vaccinations on the schedule determined by the vaccine's licensed DOI and local regulation is important to ensure sustained immunity. However, in order to maximise rabies protection in the general dog population, the first priority should be to ensure as many dogs as possible have received at least two vaccinations.

\section{References}

Aghomo, H. O., O. O. Oduye and C. E. Rupprecht, 1990: The serological response of young dogs to the Flury LEP strain of rabies virus vaccination. Vet Res Comm. 14, 415-425. Aubert, M.F.A, 1992: Practical significance of rabies antibodies in cats and dogs. Rev Sci Tech OIE. 11, 735-760.

Barth, R., and O. Jaeger, 1977: Zur prufung der immunitatsdauer von tollwutkombinationsvaccinen am hund. Blauen Hefte fur den Tierdrzt. 57, 337-346.

Berndtsson, L. T., A. K. J. Nyman, E. Rivera, B. Klingeborn. 2011. Factors associated with the success of rabies vaccination of dogs in Sweden. Acta Vet Scand. 53, 22. doi: $10.1186 / 1751-0147-53-22$.

Brown, C. M., L. Conti, P. Ettestad, M. J. Leslie, F. E. Sorhage, B. Sun, 2011: Compendium of animal rabies prevention and control, 2011. J Am Vet Med Assoc. 239, 609-617. 
Brown, A. L., D. L. Merry, W. H. Beckenhauer, 1973: Modified-live virus rabies vaccine

348 produced from Flury high egg passage virus grown on an established canine kidney cell line:

349 three-year duration of immunity study in dogs. Am J Vet Res. 34, 1427-1432.

350 Clark, K. A., and P. J. Wilson, 1996: Postexposure rabies prophylaxis and preexposure rabies

351 vaccination failure in domestic animals. J Am Vet med Assoc. 208, 1827-1830.

352 Cliquet, F., Y. Verdier, L. Sagn'e, M. Aubert, J. L. Schereffer, M. Selve, M. Wasniewski, and 353 A. Servat, 2003: Neutralising antibody titration in 25,000 sera of dogs and cats vaccinated against rabies in France, in the framework of the new regulations that offer an alternative to quarantine. Rev Sci Tech OIE. 22 (3), 857-866.

David, D., M. Bellaiche, and B. A. Yakobson, 2010: Rabies in two vaccinated dogs in Israel.

Vet Rec. 167, 907-908

358

David, D., N. Dveres, B. A. Yakobson, and I. Davidson, 2009: Emergence of dog rabies in northern regions of Israel. Epidemiol Infect. 137 (4), 544-548

David, D., and B. A. Yakobson, 2011: Review Article: Dogs serve as a reservoir and transmit

361 rabies in Israel. Is history repeating itself? Israel J Vet Med. 66 (1), 3-8.

362 Day, M. J., M. C. Horzinek and R. D. Schultz, 2010: World Small Animal Veterinary Association guidelines for the vaccination of dogs and cats. J Small Anim Pract. 51 (6), 338356

Dean, A. G., K. M. Sullivan, and M. M. Soe, 2015: OpenEpi: Open source epidemiologic statistics for public health. Available at: http://www.OpenEpi.com (accessed 13 Nov 2015).

367 European Food Safety Authority (ESFA). 2006. Assessment of the risk of rabies introduction into the UK, Ireland, Sweden, Malta, as a consequence of abandoning the serological test measuring protective antibodies to rabies. Scientific Opinion of the Scientific Panel on Animal Health and Welfare. ESFA J. 436, 1-54. 
371 Food and Agriculture Organization of the United Nations (FAO), 2001: Israel: Animal

372 Diseases Ordinance (New Version) 1985. FAOLEX - legislative database of FAO Legal

373 Office. Available online: http://faolex.fao.org/cgi-

374 bin/faolex.exe?rec $\mathrm{id}=015865 \&$ database=faolex\&search $\_$type=link\&table=result\&lang=eng

375 \&format_name=@ERALL (accessed 4 Nov 2015).

376 Ganiere, J. P., G. Andre-Fontaine, J. Blancou, M. Artois, and A. Aubert, 1989: Vaccination antirabique de chien et du chat: taux d'anticorps et resistance a l'epreuve virulente deux ans apres l'injection de rappel d'un vaccin additionne d'adjuvant. Rev Med Vet-Toulouse. 140, 281-285.

380 Israel Ministry of Agriculture and Rural Development, 1934: Rabies Ordinance, 1934:

Ordinance determining provisions for prevention of the disease of rabies. Available online: http://www.vetserveng.moag.gov.il/NR/rdonlyres/DAEEB34A-6DF3-4DB1-955B0D400DC07F0E/1022/RabiesOrdinance.pdf. (accessed 4 Nov 2015).

Israel Ministry of Agriculture and Rural Development, 2015: [Rabies regulations including supervision of Dogs]. Available online:

http://www.vetserv.moag.gov.il/Vet/hukim/takanot/takanot_kalevet/default.htm (accessed 4

387 Nov 2015).

Klevar, S., H. R. Høgåsen, R. K. Davidson, I. S. Hamnes, L. Treiberg Berndtsson, A. Lund. 2015. Cross-border transport of rescue dogs may spread rabies in Europe. Vet Rec. Published online 25 June 2015. doi: 10.1136/vr.102909.

391 Lankau, E. W., N. J. Cohen, E. S. Jentes, L. E. Adams, T. R. Bell, J. D. Blanton, D. Buttke, G. G. Galland, A. M. Maxted, D. M. Tack, S. H. Waterman, C. R. Rupprecht, and N. Marano, 2014: Prevention and control of rabies in an age of global travel: A review of US travel- and trade-associated rabies cases. Zoonoses Public Health. 61(5), 305-316. doi: 10.1111/zph.12071. 

Infect. 120, 165-169.

Nobel, T. A., and F. Neumann, 1962: Laboratory diagnosis of rabies in Israel, 1949-1961.

Refu Vet. 19, 116-12

400 Petrovsky, N. and J. C. Aguilar, 2004: Vaccine adjuvants: Current state and future trends. 401 Immunol Cell Biol. 82, 488-496.

402 Sikes, R. K., G. V. Peacock, P. Acha, R. J. Arko, and R. Dierks, 1971: Rabies vaccines: duration of immunity study in dogs. J Am Vet Med Assoc. 159, 1491-1499

Smith, J. S., P. A. Yager PA, and G. M. Baer, 1973: A rapid reproducible test for determining 405 rabies neutralizing antibody. B World Health Organ. 48, 535-541.

406 U. S. Department of Agriculture (USDA), 2015: IRegs for Animal Exports. Available at: 407 https://www.aphis.usda.gov/wps/portal/aphis/ourfocus/importexport/!ut/p/a1/04 Sj9CPyks sy0xPLMnMz0vMAfGjzOK9 D2MDJ0MjDzd3V2dDDz93HwCzL29jAwCTYAKIvEo8DYlTrzu60HibmPgYGBiYWRgaeLk4eLuaWvgYGnGXH6DXAARwNC-

410 sP10 AqAfkArACfE8EK8LihIDc0NMIg0xMA3Z0EkQ!!/?1dmy\&urile=wcm\%3apath\%3a\%2Faphi

411 s content library $\% 2 \mathrm{Fsa}$ our focus $\% 2 \mathrm{Fsa}$ animal health $\% 2 \mathrm{Fsa}$ export from us $\% 2 \mathrm{Fsa}$ live ani

412 mals\%2Fct iregs animal exports home (accessed 30 June 2015).

413 World Health Organization (WHO), 1992: Expert committee on rabies, 8th report. WHO

414 Technical Report Series 824. World Health Organization, Geneva.

415 World Health Organization (WHO), 2015: Rabies: Control and Elimination Strategy.

416 Available at: http://www.who.int/rabies/control/en/ (accessed 4 Nov 2015).

417 World Organisation for Animal Health (OIE), 1996: Chapter 3.1.5. Rabies. In: International 418 animal health code: updates 1993-1996. World Organisation for Animal Health, Paris.

419 World Organisation for Animal Health (OIE), 2013: Chapter 2.1.13. Rabies. In: OIE 420 terrestrial manual. World Organisation for Animal Health, Paris. Available at: 

Jun 2014). Yakobson, B. A., D. David, and F. Aldomy, 2004: Rabies in Israel and Jordan. In: King, A. A., A. R. Fooks, M. Aubert and A. I. Wandeler (eds), Historical Perspective of Rabies in 425 Europe and the Mediterranean Basin, pp. 171-183. World Organisation for Animal Health 426 (OIE) in conjunction with the WHO. Paris, Geneva.

427 Yakobson, B. A., R. J. King, S. Amir, N. Dveres, N. Sheichat, D. Rotenberg, Z. Mildenberg, 428 D. David, 2006: Rabies vaccination programme for red fox (Vulpes vulpes) and golden 429 jackals (Canis aureus) in Israel (1999-2004). Dev Biol (Basel). 125, 133-140.

430 Yakobson, B., D. L. Manalo, K. Bader, S. Perl, A. Haber, B. Shahimov, and N. Shechat, 431 1998: An epidemiological retrospective study of rabies diagnosis and control in Israel 1948432 1997. Israel J Vet Med. 53, 114-127.

Zalan, E., C. Wilson, and D. Pukitis, 1979: A microtest for quantitation of rabies virus neutralizing antibodies. J Biol Stand. 7, 213-220.

435 Zanoni, R. G., P. Bugnon, E. Deranleau, T. M. V. Nguyen, D. Brügger. 2010. Walking the 436 dog and moving the cat: rabies serology in the context of international pet travel schemes.

437 Schweizer Archiv fur Tierheilkunde. 152(12), 561-568.

\section{$438 \quad$ Figure Legends}

439 Figure 1: Distribution of gap between most recent rabies vaccination and presentation for pre440 travel titre.

441 Figure 2: Estimated risk of failure to have an adequate RVNA titre for different scenarios, 442 estimated using the logistic regression model. "Gap" refers to the time passed between the 443 most recent rabies vaccination and presentation for pre-travel titre. 
Table 1. Preliminary analysis of variables associated with adequacy of rabies neutralizing antibody titre in dogs presenting for travel

446 certification, Israel - Jan. 2010 to May 2014

\section{(a) INITIAL UNIVARIATE ANALYSES}

\begin{tabular}{|c|c|c|c|c|c|c|}
\hline \multirow[t]{3}{*}{ (a) INITAL UNIVARIA TE AN } & Variable (exposure factor) & & $\mathbf{n}$ & \%'exposed' & \multicolumn{2}{|c|}{ \&Yates' Corrected $\mathrm{Chi}^{2}$ p-value ( 2 tail) } \\
\hline & 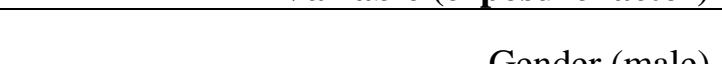 & Cases & $276^{*}$ & $49.3 \%$ & $112(081$ to 153$)$ & \\
\hline & Gender (male) & Controls & $344^{\star}$ & $46.5 \%$ & $1.12(0.81$ to 1.53$)$ & $\mathrm{p}=0.546$ \\
\hline & \multirow{2}{*}{ Number of previous vaccinations (Only one) } & Cases & 346 & $85.0 \%$ & \multirow{2}{*}{$10.38(7.18$ to 15.00$)$} & \multirow{2}{*}{$\mathrm{p}<0.0001^{\$}$} \\
\hline & & Controls & 346 & $35.3 \%$ & & \\
\hline & \multirow{2}{*}{ Age at most recent vaccination ( $\leq 15$ months) } & Cases & 346 & $62.4 \%$ & \multirow{2}{*}{$4.39(3.18$ to 6.05$)$} & \multirow{2}{*}{$\mathrm{p}<0.0001^{\$}$} \\
\hline & & Controls & 346 & $27.5 \%$ & & \\
\hline & \multirow{2}{*}{ Gap between vaccination and titre (>60 days) } & Cases & 346 & $80.3 \%$ & \multirow{2}{*}{2.71 (1.93 to 3.82$)$} & \multirow{2}{*}{$\mathrm{p}<0.0001^{\$}$} \\
\hline & & Controls & 346 & $60.1 \%$ & & \\
\hline
\end{tabular}

(b) STRATIFIED ANALYSES: effect of age at most recent vaccination for dogs with a different number of previous vaccinations.

\begin{tabular}{|c|c|c|c|c|c|c|}
\hline & Variable (exposure factor) & & $\mathbf{n}$ & \%'exposed' & & \\
\hline \multirow{2}{*}{$\begin{array}{l}\text { STRATUM: } \\
\text { only one vaccination }\end{array}$} & \multirow{2}{*}{ Age at most recent vaccination $\leq 15$ months } & Cases & 294 & $72.4 \%$ & \multirow{2}{*}{$1.14(0.72$ to 1.82$)$} & \multirow{2}{*}{$\mathrm{p}=0.6509$} \\
\hline & & Controls & 122 & $69.7 \%$ & & \\
\hline \multirow{2}{*}{$\begin{array}{l}\text { STRATUM: } \\
>1 \text { vaccination }\end{array}$} & \multirow{2}{*}{ Age at most recent vaccination $\leq 15$ months } & Cases & 52 & $5.8 \%$ & \multirow{2}{*}{$1.31(0.35$ to 4.94$)$} & \multirow{2}{*}{$\mathrm{p}=0.9138^{*}$} \\
\hline & & Controls & 224 & $4.5 \%$ & & \\
\hline
\end{tabular}

(c) STRATIFIED ANALYSES: effect of number of previous vaccinations for dogs most recently vaccinated at different ages.

\begin{tabular}{|c|c|c|c|c|c|c|}
\hline & Variable (exposure factor) & & $\mathbf{n}$ & \%'exposed' & & \\
\hline \multirow{2}{*}{$\begin{array}{r}\text { STRATUM: } \\
\text { vaccination at } \leq 15 \text { months }\end{array}$} & \multirow{2}{*}{ Only one vaccination received } & Cases & 216 & $98.6 \%$ & \multirow{2}{*}{$8.35(2.24$ to 31.09$)$} & \multirow{2}{*}{$\mathrm{p}=0.0012 *, \$$} \\
\hline & & Controls & 95 & $89.5 \%$ & & \\
\hline STRATUM: & \multirow{2}{*}{ Only one vaccination received } & Cases & 130 & $62.3 \%$ & \multirow{2}{*}{$9.56(5.81$ to 15.72$)$} & \multirow{2}{*}{$\mathrm{p}<0.0001^{\$}$} \\
\hline vaccination at $>15$ months & & Controls & 251 & $14.7 \%$ & & \\
\hline
\end{tabular}

$447 \quad \neq$ some cases did not have gender recorded

$448 \quad$ *Fisher exact $p$-value used here because conditions not met to use $X^{2}$

449 Significant at $\alpha<0.05$. 


\begin{tabular}{|c|c|c|c|}
\hline $\begin{array}{c}\text { Number of previous } \\
\text { vaccinations }\end{array}$ & Group & $\begin{array}{l}\text { Mean age* in } \\
\text { months }( \pm \text { SE) }\end{array}$ & p-value** \\
\hline \multirow{3}{*}{$\begin{array}{l}\geq 1 \text { vaccinations } \\
\text { (all dogs in study) }\end{array}$} & Cases $(n=346)$ & $20.5 \pm 1.6 \mathrm{mo}$ & \multirow{2}{*}{$<0.0001^{\$}$} \\
\hline & Controls $(n=346)$ & $40.7 \pm 2.0 \mathrm{mo}$ & \\
\hline & Cases \& controls $(n=692)$ & $30.6 \pm 1.3 \mathrm{mo}$ & \\
\hline \multirow{3}{*}{$\begin{array}{l}\text { Only } 1 \text { vaccination } \\
\text { (60\% of all dogs in study) }\end{array}$} & Cases $(n=294)$ & $16.0 \pm 1.4 \mathrm{mo}$ & \multirow{2}{*}{0.4399} \\
\hline & Controls $(n=122)$ & $14.2 \pm 1.8 \mathrm{mo}$ & \\
\hline & Cases \& controls $(n=416)$ & $15.5 \pm 1.1 \mathrm{mo}$ & \\
\hline \multirow{3}{*}{$\begin{array}{c}>1 \text { vaccination } \\
\text { (40\% of all dog in study) }\end{array}$} & Cases $(n=52)$ & $45.8 \pm 5.5 \mathrm{mo}$ & \multirow{2}{*}{0.1273} \\
\hline & Controls $(n=224)$ & $55.1 \pm 2.4 \mathrm{mo}$ & \\
\hline & Cases \& controls $(n=276)$ & $53.2 \pm 2.2 \mathrm{mo}$ & \\
\hline
\end{tabular}

452

453

454

455

456

457

458

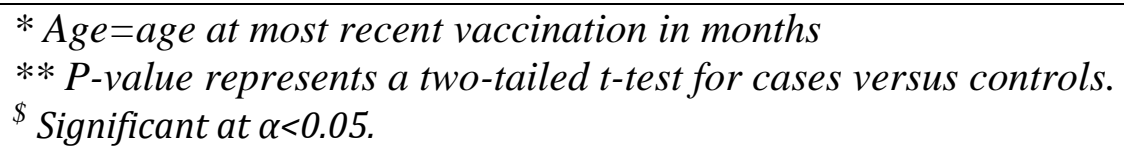

Table 3: Parameter estimates of exploratory multivariable logistic regression models for likelihood of failing to achieve an adequate RVNA titre in dogs presented for travel certification

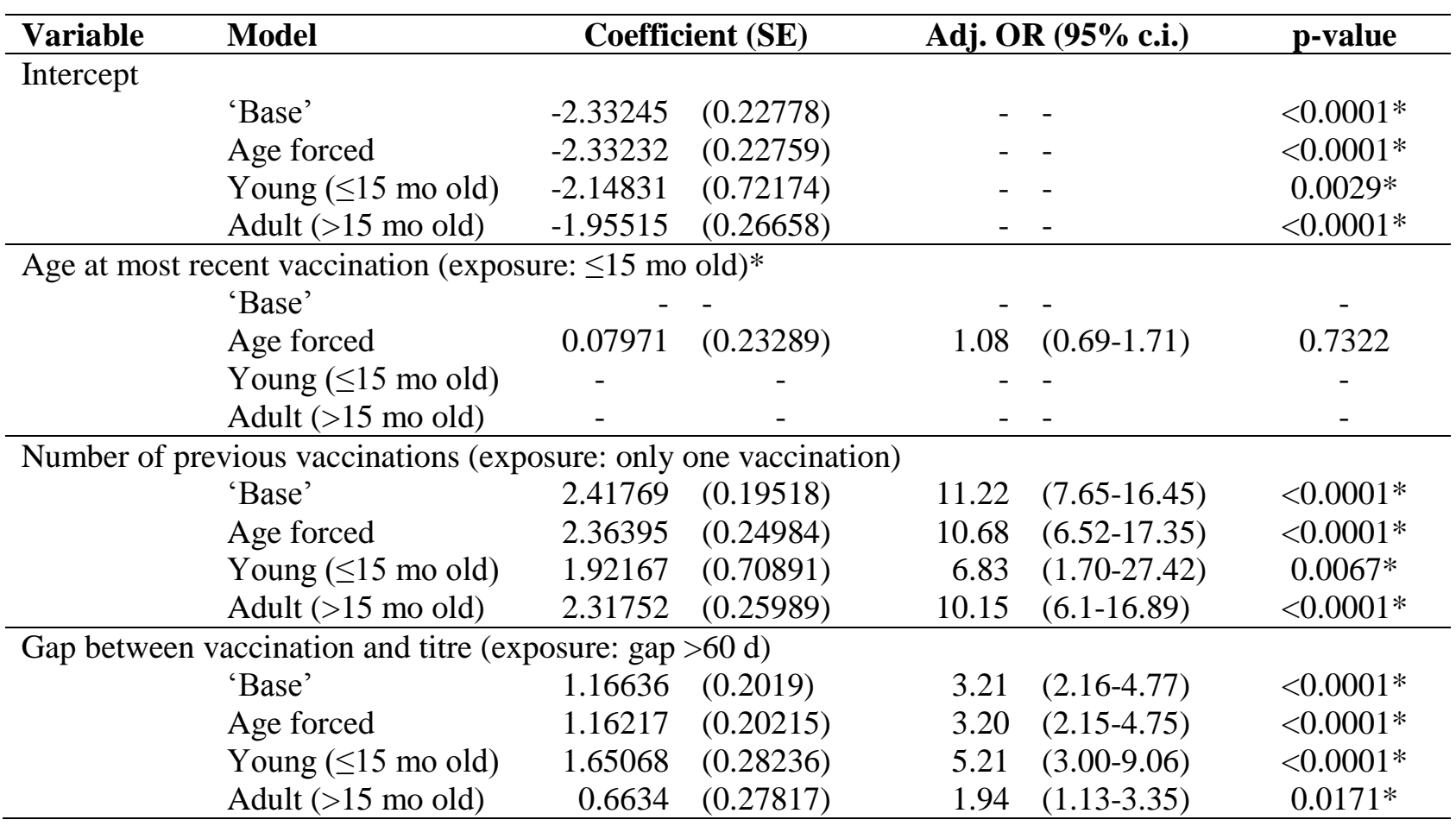

459 *Coefficients are deviation of "exposure" level listed from the alternative referent level for each

460 binomial variable ( $\leq 15$ mo old: $>15$ mo old; only one vaccination: >1 vaccination; gap $\leq 60$ d: gap

$461>60 d)$

$462 \quad * *$ Significant at $\alpha<0.05$.

463 
464 Table 4: Parameter estimates of final multivariable logistic regression model for likelihood of

465 failing to achieve an adequate RVNA titre in dogs presented for travel certification

Variable and level

Coefficient (SE)

Adjusted OR (95\% CI)

p-value

\begin{tabular}{|c|c|c|c|}
\hline \multirow{2}{*}{\multicolumn{4}{|c|}{$\begin{array}{l}\text { Intercept } \\
\text { Age at most recent vaccination ("Age") }\end{array}$}} \\
\hline & & & \\
\hline Young $(\leq 15$ months $)$ & $-0.55717(0.34353)$ & $0.57(0.29-1.12)$ & 0.1048 \\
\hline Adult (>15 months) & Ref. & 1.0 & \\
\hline \multicolumn{4}{|l|}{ Number of previous vaccinations } \\
\hline Only one vaccination & $2.2738(0.24489)$ & $9.72(6.01-15.7)$ & $<0.0001 * *$ \\
\hline$>1$ vaccination & Ref. & 1.0 & \\
\hline \multicolumn{4}{|l|}{ Gap between vaccination and titre } \\
\hline Long gap (>60 days) & $0.65557(0.2762)$ & $1.93(1.12-3.31)$ & $0.0176^{* *}$ \\
\hline Short gap ( $\leq 60$ days) & Ref. & 1.0 & \\
\hline Interaction: Age x Gap & $0.99766(0.39562)$ & $2.71(1.25-5.89)$ & $0.0117 * *$ \\
\hline
\end{tabular}

466

$*$ Overall model: Deviance $=729.12$; p-value $=0.1289 ;$ Degrees of freedom $=687$. As deviance

467 reduces the better the correspondence between the observed and fitted values, a non-

468 significant $\mathrm{p}$-value indicates no gross deficiencies with the overall model fit.

$469 * *$ Significant at $\alpha<0.05$.

470 